\title{
ALGORITMA VIGENERE CIPHER DAN HILL CIPHER DALAM APLIKASI KEAMANAN DATA PADA FILE DOKUMEN
}

\author{
Akim Manaor Hara Pardede ${ }^{1}$, Hotler Manurung ${ }^{2}$, Dina Filina ${ }^{3}$ \\ ${ }^{1,2,3}$ Program Studi Sistem Informasi, STMIK KAPUTAMA \\ Jl. Veteran 4A-9A,Binjai \\ *akimmhp@live.com
}

\begin{abstract}
Abstrak
Perkembangan kriptografi terus berlanjut walaupun algoritma yang terkemuka dan dinilai kompleks sudah mulai bisa dipecahkan. Algoritma- algoritma kriptografi klasik seperti Hill Cipher dan Vigenere Cipher pin memiliki kelemahan akan kriptanalisis. Algoritma hill cipher dan vigenere cipher merupakan salah satu metode dari beberapa metode yang digunakan untuk melakukan kerahasian data, hill cipher adalah algoritma keamanan data menggunakan perhitungan perkalian matriks, sedangkan vigenere cipher adalah algoritma yang melakukan enkripsi sekaligus sebuah teks yang terdiri dari beberapa huruf. Jika kedua algoritma diatas dikombinasikan dalam sebuah aplikasi keamanan data, maka akan lebih sulit memecahkan sandinya bila dibandingkan dengan hanya menggunakan satu algoritma saja. Penggabungan antara dua algoritma tersebut menjadi sebuah solusi untuk memperkuat algoritma menjadi lebih sulit untuk dapat dipecahkan dan untuk mengecoh kriptanalisis. Filet eks yang telah diamankan menggunakan Algoritma Vigenere Cipher akan diamankan lagi menggunakan Algoritma Hill Cipher. Implementasi sistem menggunakan perangkat lunak Visual Basic.Net 2010. Hasil dari sistem ini berupa file yang ter-enkripsi (cipherfile) yang tidak bisa dimengerti. Kemudian fileteks kembali normal setelah di-dekripsi.
\end{abstract}

Kata kunci: Hill Cipher, Kriptografi, Vigenere Cipher, Visual Basic.Net 2010

\section{PENDAHULUAN 1.1 Latarbelakang}

Dalam sistem keamanan data dikenal sebuah metode enkripsi yang mempunyai kode-kode pengamanan untuk mengacak data dan juga mempunyai kode- kode untuk mengembalikan data yang teracak ke data yang sebenarnya. Enkripsi bisa diartikan dengan chiper atau kode, dimana pesan asli (plaintext) diubah menjadi kode-kode tersendiri sesuai metode yang disepakati oleh kedua belah pihak, baik pihak pengirim pesan maupun penerima pesan. Aplikasi-aplikasi keamanan data sudah banyak diterapkan dan digunakan dalam kehidupan sehari-hari, khususnya pada aplikasi smartphone android yang pada saat ini menjadi kebutuhan primer bagi kita semua.

Penelitian yang dilakukan oleh F. Wiwiek Nurwiyati dan Indra Yatini B (Oktober 2013) dengan judul "Enkripsi Dekripsi Data Menggunakan Metode Stream
Dan Vigenere Cipher". Dengan hasil sebagai berikut: Teknik kriptografi enkripsi dekripsi dengan menggunakan metode Stream dan Vigenere Cipher dapat melindungi data dimana program akan melakukan proses enkripsi dan deskripsi menggunakan dua kunci yang berbeda satu kunci dibangkitkan dengan karakter plain text dan satu lagi di inputkan secara manual.

Algoritma enkripsi akan memberikan hasil yang berbeda tergantung pada kunci yang digunakan. Mengubah kunci dari enkripsi akan mengubah output (keluaran) dari algoritma enkripsi. Setelah itu ciphertext kemudian ditransmisikan oleh pengirim. Kemudian akan dilakukan proses dekripsi, yaitu sebuah proses untuk mengembalikan teks yang telah acak menjadi kebentuk semula dengan algoritma dan kunci yang sama. Dalam hal ini dilakukan oleh penerima, sehingga akan kembali menjadi sebuah informasi yang dapat dipahami oleh penerima. 
Algoritma hill cipher dan vigenere cipher merupakan salah satu metode dari beberapa metode yang digunakan untuk melakukan kerahasian data, hill cipher adalah algoritma keamanan data menggunakan perhitungan perkalian matriks, sedangkan vigenere cipher adalah algoritma yang melakukan enkripsi sekaligus sebuah teks yang terdiri dari beberapa huruf. Jika kedua algoritma diatas dikombinasikan dalam sebuah aplikasi keamanan data, maka akan lebih sulit memecahkan sandinya bila dibandingkan dengan hanya menggunakan satu algoritma saja.

\subsection{Rumusan Masalah}

Berdasarkan latar belakang masalah yang ada diatas, maka penulisan merumuskan masalah sebagai berikut :

1. Dengan menggunakan Algoritma Vigenere Cipher dan Algoritma Hill Cipher, bagaimana merancang keamanan data file teks agar data tersebut tidak mudah dipecahkan.

2. Merancang keamanan data file teks dengan mengkombinasikan Algoritma Vigenere Cipher dan Algoritma Hill Cipher.

\subsection{Tujuan Penelitian}

Tujuan penelitian ini antara adalah :

1. Merancang keamanan data file teks menggunakan algoritma Vigenere Cipher dan Hill Cipher.

2. Menghasilkan suatu sistem yang mampu melindungi data dan merahasiakannya dengan menggunakan algoritma Vigenere Cipher dan Hill Cipher.

\section{LANDASAN TEORI}

\subsection{Algoritma Vigenere Cipher}

Menurut Sadikin (2012, h. 48) sandi vigenere merupakan sistem sandi polialfabetik yang sederhana, sistem sandi polialfabetik mengenkripsikan sekaligus sebuah teks yang terdiri dari beberapa huruf. Sandi vigenere menggunakan subtitusi dengan fungsi shift.

Sedangkan menurut Ariyus (2006, h. 33) pada teknik subtitusi vigenere setiap ciphertext bisa memiliki banyak kemungkinan plaintextnya. Teknik ini bisa dilakukan oleh dua cara yaitu : angka dan huruf.

Cipher ini hanya bergantung pada metodologi confusion untuk membuat cipher text. Pola berulang pada plaintext tidak melalui difusi, melainkan hanya dikamuflase oleh seri dari pergeseran Caesar cipher. Vigenere cipher dianggap unbreakable selama hampir 300 tahun. Tetapi akhirnya metode untuk memecahkannya ditemukan oleh Kasiski dan Kerckhoff. Kedua metode berdasar pada fakta bahwa kuncinya berulang dan pada umumnya bahasa yang digunakan sehari-hari bersifat repetitif. Jika pesan jauh lebih panjang dari kunci, pada akhirnya kunci akan mengenkripsi satu kumpulan huruf yang sama yang sebelumnya telah digunakan dan dienkripsi oleh kunci yang sama. Hal ini akan menciptakan suatu pola yang berisi kumpulan huruf yang berulang. Dengan mencari frekuensi antara kumpulan huruf yang berulang dan memfaktorkannya, bisa ditemukan panjang kunci. Jika panjang kunci sudah diketahui, kunci akan dengan mudah diketahui dengan menggunakan analisis frekuensi pada setiap kumpulan Caesar cipher. Makin panjang kunci, akan makin sulit dan makin panjang proses penemuan kunci. Faktanya, jika kuncinya paling tidak sama panjang dengan panjang plaintext, cipher text kebal dari serangan tersebut. Cipher di mana panjang kunci sama dengan panjang pesan disebut one time pad.

\section{a. Angka}

Teknik subtitusi vigenere dengan menggunakan angka dilakukan dengan menukarkan huruf dengan angka, hampir sama dengan kode geser.

Kunci dengan 5 huruf kode jika ditukar dengan angka akan menjadi $\mathrm{K}=(10,20,13,2$, 8), dan teks-aslinya " STMIK KAPUTAMA BINJAI".

$\left.\begin{array}{|c|c|c|c|c|c|c|c|c|}\hline \mathrm{S} & \mathrm{T} & \mathrm{M} & \mathrm{I} & \mathrm{K} & \mathrm{K} & \mathrm{A} & \mathrm{P} & \mathrm{U} \\ \hline 18 & 19 & 12 & 8 & 10 & 10 & 0 & 15 & 20 \\ \hline 10 & 20 & 13 & 2 & 8 & 10 & 20 & 13 & 2 \\ \hline 2 & 13 & 0 & 10 & 18 & 20 & 20 & 2 & 22 \\ \mathrm{C} & \mathrm{N} & \mathrm{A} & \mathrm{K} & \mathrm{S} & \mathrm{U} & \mathrm{U} & \mathrm{C} & \mathrm{W}\end{array}\right]$

\begin{tabular}{|c|c|c|c|c|c|c|c|c|c|}
\hline T & A & M & A & B & I & N & J & A & I \\
\hline 19 & 0 & 12 & 0 & 1 & 8 & 13 & 9 & 0 & 8 \\
\hline 8 & 10 & 20 & 13 & 2 & 8 & 10 & 20 & 13 & 2 \\
\hline I & 10 & 6 & 13 & 3 & 16 & 23 & 3 & 13 & 10 \\
B & K & G & N & D & Q & X & D & N & K \\
\hline
\end{tabular}




\section{Teks-asli : STMIK KAPUTAMA BINJAI \\ Kunci $:(10,20,13,2,8)$ \\ Teks-kode : \\ CNAKSUUCWBKGNDQXDNK \\ b. Huruf}

Untuk mengenkripsikan pesan dengan kode vigenere digunakan tabula recta (disebut juga bujursangkar vigenere). Kolom paling kiri dari bujursangkar menyatakan huruf-huruf kunci, sedangkan baris paling atas menyatakan huruf-huruf plainteks. Setiap baris di dalam bujursangkar menyatakan hurufhuruf cipherteks yang diperoleh dengan Caesar Cipher, yang mana jauh pergeseran huruf plainteks ditentukan nilai desimal oleh huruf kunci tersebut (di sini, $a=0, b=1, c=$ $2, \ldots, \mathrm{z}=25)$. Sebagai contoh, huruf kunci $\mathrm{c}$ (= 2) menyatakan huruf plainteks digeser sejauh 2 huruf ke kanan (dari susunan alfabetnya).

Bujur sangkar Vigènere digunakan untuk memperoleh cipherteks dengan menggunakan kunci yang sudah ditentukan. Jika panjang kunci lebih pendek dari pada panjang plainteks, maka kunci diulang penggunaannya (sistem periodik). Secara matematis enkripsi dengan kode Vigenere bisa dinyatakan sebagai berikut:

Algoritma enkripsi vigenere cipher :

$\mathrm{Ci}=(\mathrm{Pi}+\mathrm{Ki}) \bmod 26$

Algoritma dekripsi vigenere cipher :

$\mathrm{Pi}=(\mathrm{Ci}-\mathrm{Ki}) \bmod 26$

Dimana :

$\mathrm{Ci}=$ nilai desimal karakter ciphertext $\mathrm{ke}-\mathrm{i}$

$\mathrm{Pi}=$ nilai desimal karakter plaintext $\mathrm{ke}-\mathrm{i}$

$\mathrm{Ki}=$ nilai desimal karakter kunci ke-i

Salah satu kelebihan kode vigenere adalah sulitnya melakukan kapitanalisis dengan metode analisis frekuensi karena dua huruf yang sama dalam teks-kode belum tenetu bisa dideskripsikan menjadi dua huruf yang sama dalam teks-asli. Kelemahan utama kode vigenere adalah kuncinya yang pendek dan penggunaannya yang berulang-ulang. Jika kriptanalis dapat menentukan panjang kunci saja maka teks-kode dapat diperlakukan seperti rangkaian beberapa kode Kaisar.

\subsection{Algoritma Hill Cipher}

Menurut Sadikin (2012, h. 51) sandi hill merupakan sandi polyalphabet dengan menggunakan metode subtitusi dengan perhitungan perkalian matriks. Kunci pada sandi hill adalah sebuah matriks $\boldsymbol{K}$ berukuran $n$ $x n$ yang digunakan untuk mensubtitusi $n$ alphabet sekaligus.

Menurut Ariyus (2008, h. 59) kode hill termasuk salah satu kripto polialfabetik, yang berarti setiap karakter alfabet bisa dipetakan ke lebih dari satu macam karakter. Kode ini ditemukan pada tahun 1929 oleh Lester S. Hill.

\section{Teknik Dasar Hill Cipher}

Teknik Hill Cipher adalah aritmatika modulo terhadap matriks. Dalam penerapannya, Hill Cipher menggunakan teknik perkalian matriks dan teknik invers terhadap matriks. Kunci pada Hill Cipher adalah matriks $\mathrm{n} \times \mathrm{n}$ dengan $\mathrm{n}$ merupakan ukuran blok. Matriks K yang menjadi kunci ini harus merupakan matriks yang invertible, yaitu memiliki inverse $\mathrm{K}^{-1}$ sehingga:

Keterangan:

$\mathrm{K} \quad$ = Kunci

$K^{-1} \quad=$ Invers Kunci

I $\quad=$ Matriks Identitas

Kunci harus memiliki invers karena matriks $\mathrm{K}^{-1}$ tersebut adalah kunci yang digunakan untuk melakukan dekripsi .

\section{PERANCANGAN}

\subsection{Perancangan UML (Unified Modelling Language)}

Dalam bagian ini akan dijelaskan untuk mendeskripsikan apa yang harus dilakukan oleh sistem, digambarkan dalam bentuk use case yang bertujuan untuk menunjukkan alur kerja dan proses dari sistem aplikasi yang akan dibuat.

Use Case Diagram atau diagram use case merupakan pemodelan untuk menggambarkan kelakuan (behavior) sistem yang akan dibuat, diagram use case mendeskripsikan sebuah interaksi antara satu atau lebih actor dengan sistem yang akan dibuat. Proses yang akan digambarkan akan berlangsung secara terstruktur. Berikut merupakan gambaran use case diagram untuk sistem yang akan dibangun pada gambar 3.1 : 


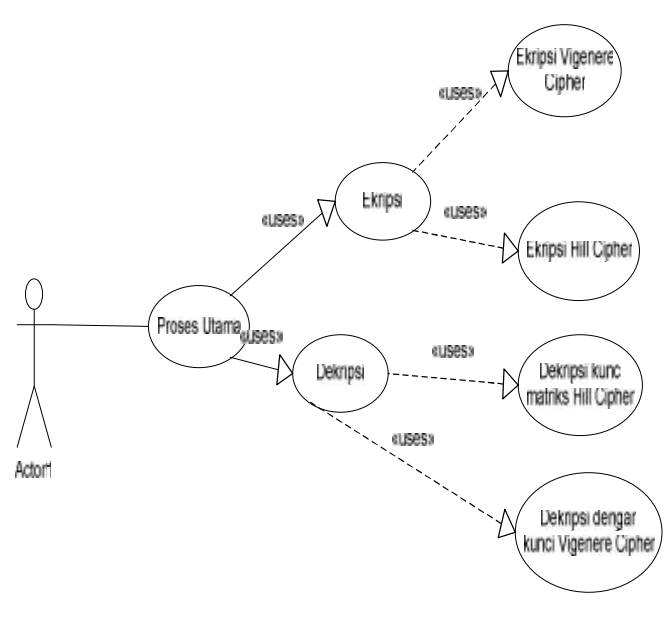

Gambar 3.1. Use Case Diagram Sistem

Gambar 1 menyatakan diagram use case sistem kriptografi untuk keamanan file teks. Use Case ini menjelaskan mengenai bagaimana proses pengenkripsian dan dekripsi menggunakan kedua algoritma vigenere cipher dan hill cipher, disini sistem menggunakan dua buah kunci yaitu kunci Poli-alfabetik dan kunci matriks. Untuk menyandikan filetext yang ingin di jaga kerahasiaannya.

\subsection{Perancangan Sistem}

Dalam merancang sistem pengamanan filetext ini penulis menggunakan algoritma vigenere cipher dan algoritma hill cipher dalam menyelesaikan masalah. Perancangan sistem ini menggunakan bagan alir (flowchart) untuk mengetahui bagaimana proses enkripsi dan dekripsi akan dirancang dalam sistem.

Pada proses dekripsi berikut ini dapat dilakukan, apabila pada proses dekripsi cipherkey sebelumnya sudah berhasil, maka dapat dilakukan proses dekripsi cipherfile. Dari kunci matriks hill cipher yang sudah diinputkan, akan dilakukan proses pencarian matriks adjoint, matriks determinan, dan matriks inverse dari determinan kunci matriks, juda inverse dari kunci matriks. Kunci matriks inverse akan dimodulokan dengan jumlah karakter code ASCII 256, kemudian setelah diperoleh kunci matriks inverse maka dapat dilakukan proses dekripsi cipherfile dengan mengkalikan kunci matriks inverse dengan file yang terenkripsi (cipherfile). Berikut merupakan flowchart dekripsi cipherfile dan cipherkey:

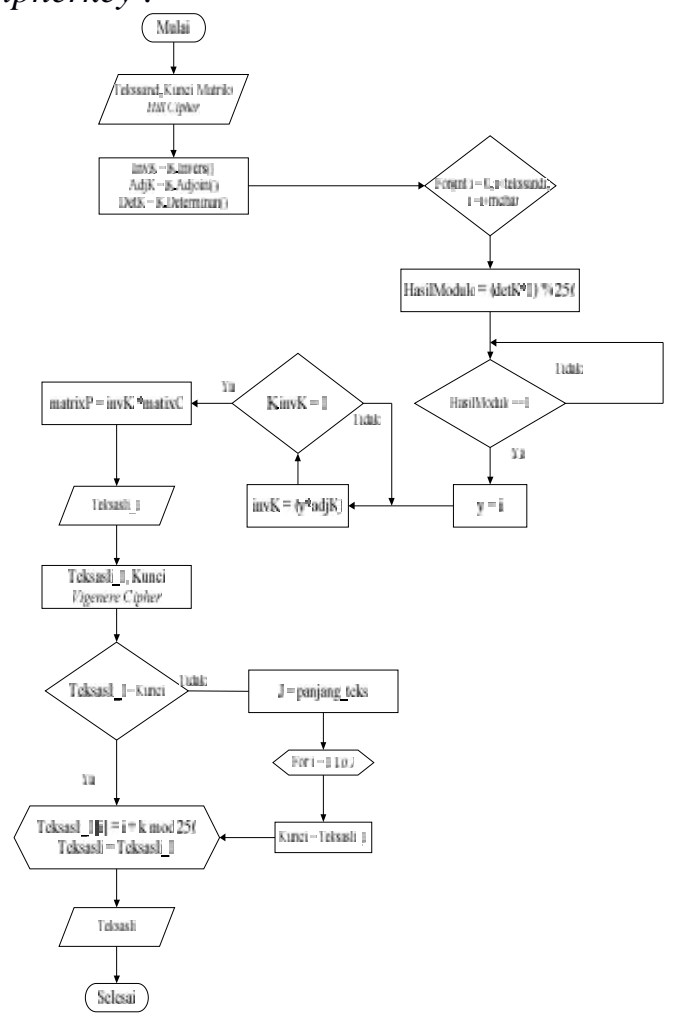

Gambar 3.2. Flowchart Dekripsi Filetext Vigenere Cipher dan Hill Cipher

\section{HASIL DAN PEMBAHASAN}

Dengan menggunakan Algoritma Hill Cipher dan Algoritma Vigenere Cipher, penulis mengharapkan dapat mengamankan fileteks dengan aman. Serta dapat membantu dalam menyandikan fileteks.

Untuk membuat suatu keputusan perlu diketahui terlebih dahulu kriteria-kriteria yang ada. Dari kriteria-kriteria tersebut kita dapat melakukan proses pengambil keputusan.

Implementasi merupakan kelanjutan dari kegiatan perancangan sistem. Tahap ini merupakan tahap meletakkan sistem supaya siap untuk di operasikan dan dapat dipandang sebagai usaha untuk mewujudkan sistem yang telah di rancang. Langkah-langkah dalam tahap implementasi ini adalah urutan kegiatan awal sampai akhir yang harus dilakukan dalam mewujudkan sistem yang telah di rancang. 


\section{Pengujian Proses Enkripsi File Dokumen}

Pada proses ini form enkripsi dapat ditampilkan dengan mengklik button Enkripsi pada form utama setelah program dijalankan. Sebelum dilakukan proses enkripsi terhadap fileteks maka hal yang pertama dilakukan adalah memilih file yang akan dienkripsi melalui button "cari"yang terdapat pada form.

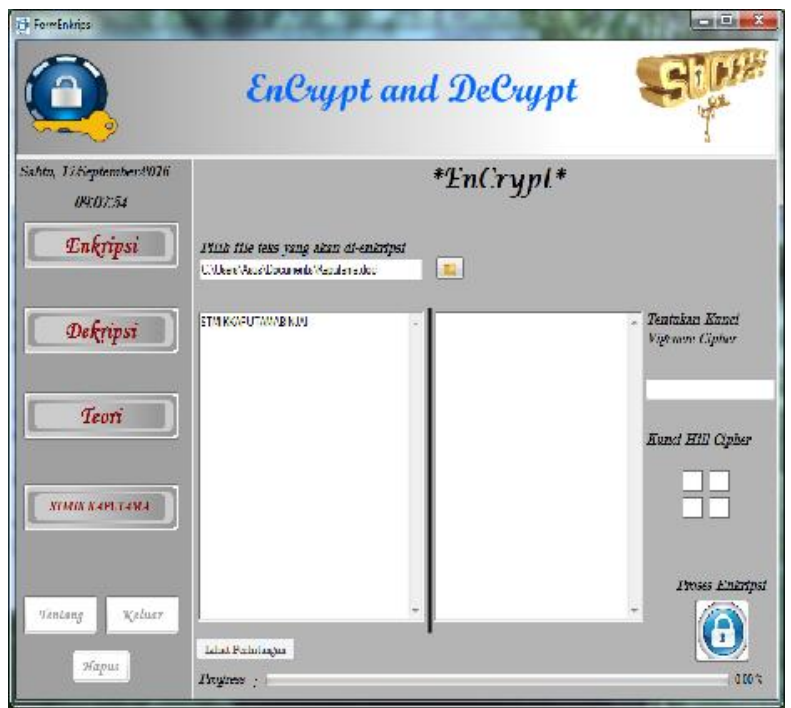

Gambar 4.1. Seteleh Proses Pemilihan Dokumen

Setelah file sudah dipilih kemudian lanjutkan proses enkripsi dengan mengisi kunci vigenere cipher dan setelah itu klik button enkripsi, seperti gambar berikut ini :

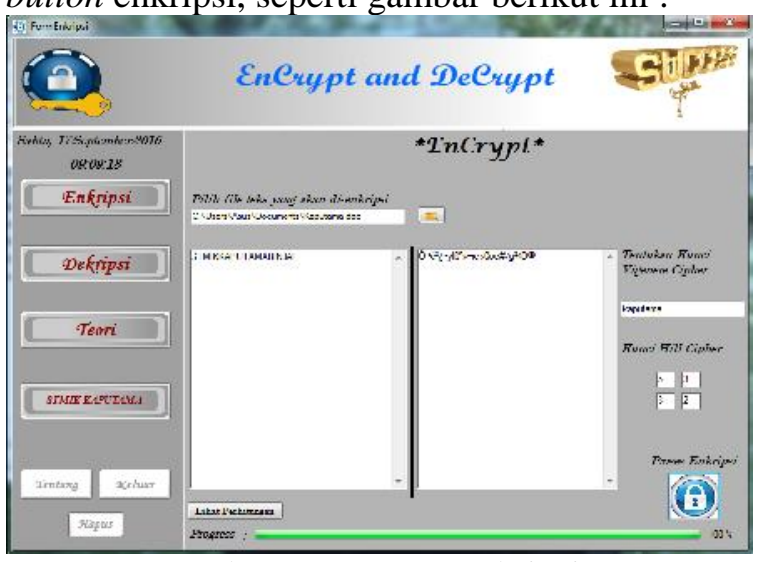

Gambar 4.2 Proses Enkripsi

Hasil pengujian dapat dilihat dari gambar sebagai berikut :

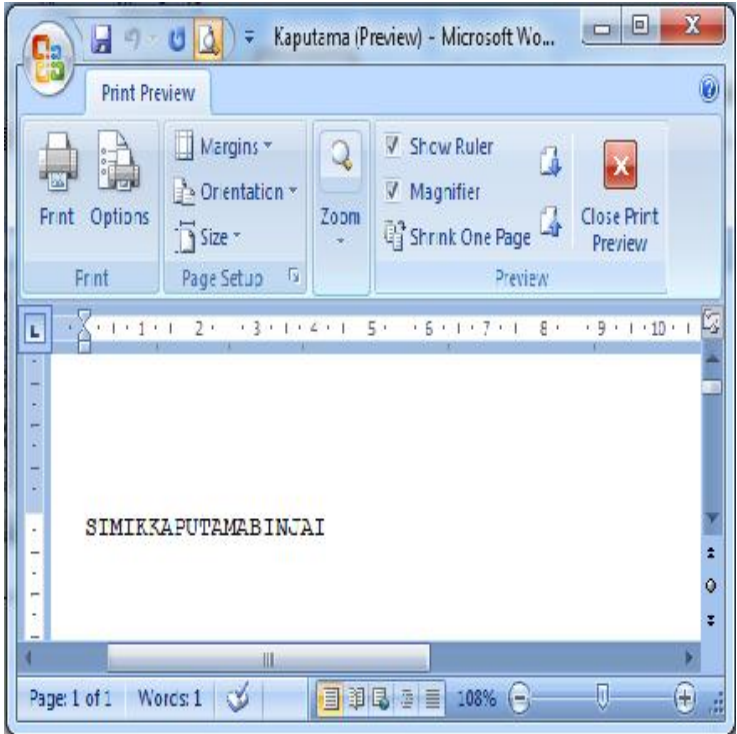

Gambar 4.3. File .docx Sebelum di Enkripsi

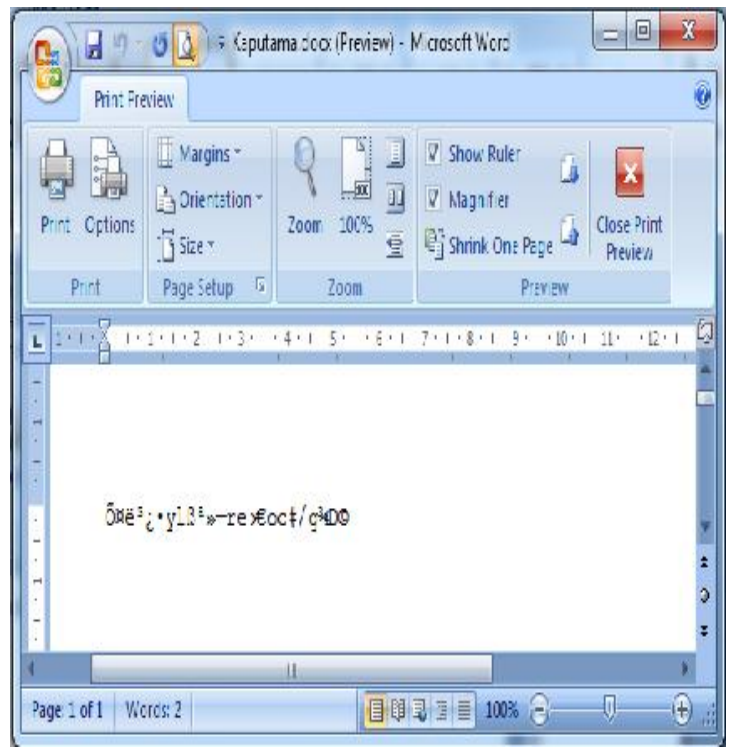

Gambar 4.4. File .docx Setelah di Enkripsi

\section{Pengujian Proses Dekripsi File Dokumen}

Pada proses ini form dekripsi dapat ditampilkan dengan mengklik button dekripsi yang terdapat pada form utama setelah program dijalankan. Sebelum dilakukan proses dekripsi terhadap file, maka hal yang pertama kali dilakukan adalah memilih file yang akan di-dekripsi dengan mengklik button "cari" yang terdapat pada form dengan ekstensi file .encrypt. 


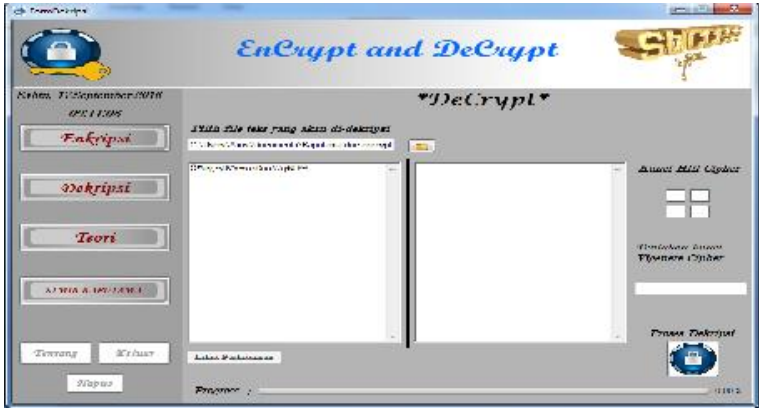

Gambar 4.5. Proses Setelah Pemilihan File Dokumen

Setelah file sudah dipilih, kemudian lanjutkan proses dekripsi dengan menginputkan kunci vigenere cipher dan setelah itu klik button dekripsi, seperti gambar berikut ini :

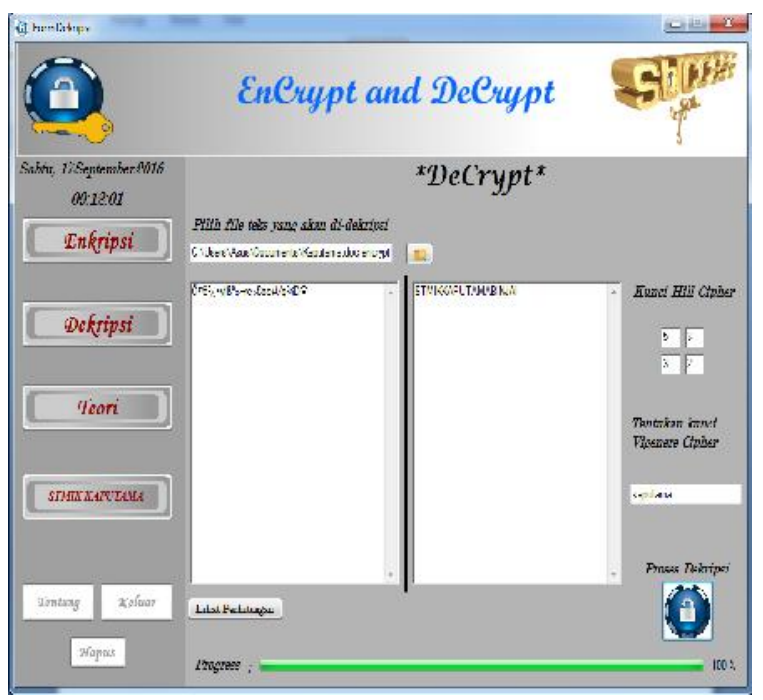

Gambar 4.6. Proses Dekripsi

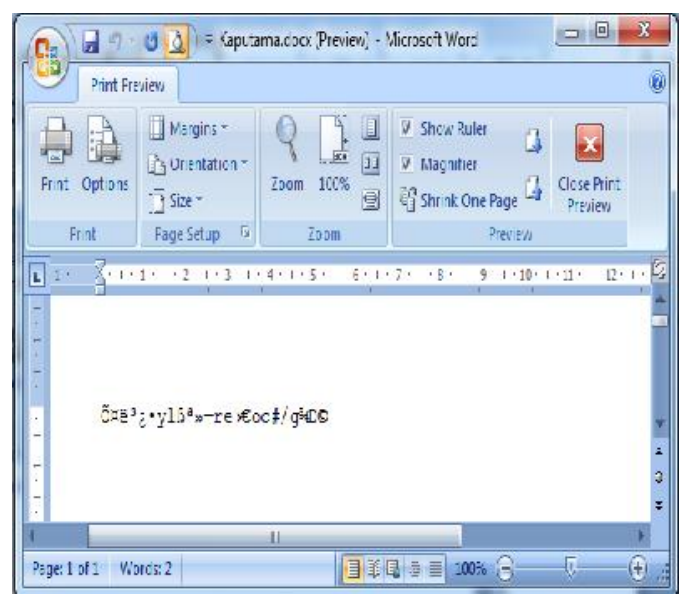

Gambar 4.7. File .docx Sebelum di Dekripsi

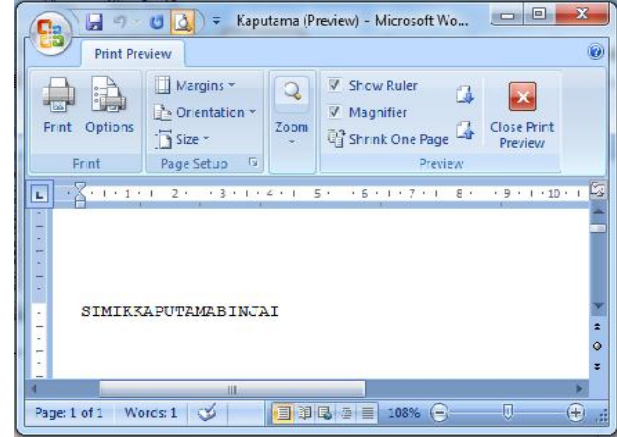

Gambar 4.8. File .docx Setelah di Dekripsi

Tabel 1. Uji Program

( Jumlah Kata yang panjang )

\begin{tabular}{|c|c|c|c|c|}
\hline $\begin{array}{l}\mathbf{N} \\
\mathbf{o}\end{array}$ & $\begin{array}{l}\text { Na } \\
\text { ma } \\
\text { File }\end{array}$ & $\begin{array}{c}\text { Jumla } \\
\text { h } \\
\text { Kata }\end{array}$ & Kunci & Ket \\
\hline 1 & $\begin{array}{l}\text { Krip } \\
\text { togr } \\
\text { afi }\end{array}$ & $\begin{array}{l}681 \\
\text { kata }\end{array}$ & $\begin{array}{l}\text { kaputam } \\
\text { a }\end{array}$ & Berhasil \\
\hline 2 & $\begin{array}{l}\text { Visu } \\
\text { al } \\
\text { Basi } \\
\text { c }\end{array}$ & $\begin{array}{l}136 \\
\text { kata }\end{array}$ & kita1234 & Berhasil \\
\hline 3 & $\begin{array}{l}\text { Enkr } \\
\text { ipsi }\end{array}$ & $\begin{array}{r}21 \\
\text { kata }\end{array}$ & kamiiiii & $\begin{array}{l}\text { Gagal ( } \\
\text { karena } \\
\text { mengguna } \\
\text { kan kunci } \\
\text { dengan } \\
\text { huruf } \\
\text { berulang- } \\
\text { ulang ) }\end{array}$ \\
\hline 4 & $\begin{array}{l}\text { Hill } \\
\text { Ciph } \\
\text { er }\end{array}$ & $\begin{array}{l}812 \\
\text { kata }\end{array}$ & binjai & $\begin{array}{l}\text { Gagal ( } \\
\text { karena } \\
\text { jumlah } \\
\text { kata yang } \\
\text { digunakan } \\
\text { melebihi } \\
\text { batas } \\
\text { maksimal } \\
\text { ) }\end{array}$ \\
\hline 5 & $\begin{array}{l}\text { Vige } \\
\text { nere }\end{array}$ & $\begin{array}{l}513 \\
\text { kata }\end{array}$ & $\begin{array}{l}1909201 \\
6\end{array}$ & Berhasil \\
\hline
\end{tabular}


Tabel 2. Uji Program Proses Enkripsi

\begin{tabular}{|c|c|c|c|}
\hline No & Plainteks & Kunci & Cipherteks \\
\hline 1 & $\begin{array}{l}\text { Kaputama } \\
\text { Binjai }\end{array}$ & kamiiiii & $\begin{array}{l}\hat{\mathrm{O}}_{1} \mathrm{ëS}^{-}+\mathrm{E} \mathrm{c}^{3} 0 \\
\} \quad \mid \mathrm{b}\end{array}$ \\
\hline 2 & $\begin{array}{l}\text { ILOVEST } \\
\text { MIKKAP } \\
\text { UTAMA } \\
\text { BINJAI }\end{array}$ & kaputama & 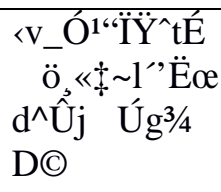 \\
\hline 3 & $\begin{array}{l}\text { Teknik } \\
\text { Informati } \\
\text { ka }\end{array}$ & kamikami & 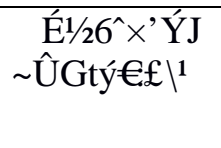 \\
\hline 4 & $\begin{array}{l}\text { Sekolah } \\
\text { Tinggi } \\
\text { Manajem } \\
\text { en } \\
\text { Informati } \\
\text { ka dan } \\
\text { Komputer }\end{array}$ & kakakaka & 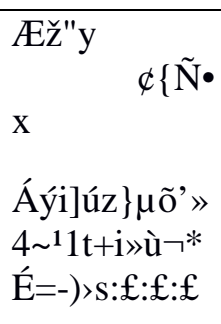 \\
\hline 5 & STMIK & 16092016 & $2 \div\{(\tilde{\mathrm{n}}-\ddot{\mathrm{Y}}$ \\
\hline
\end{tabular}

Tabel 3. Uji Program Proses Dekripsi

\begin{tabular}{|c|c|c|c|c|}
\hline $\begin{array}{l}\mathbf{N} \\
\mathbf{0}\end{array}$ & $\begin{array}{c}\text { Plain } \\
\text { teks }\end{array}$ & Kunci & $\begin{array}{c}\text { Cipherte } \\
\text { ks }\end{array}$ & Ket \\
\hline 1 & $\begin{array}{c}\text { Ô!ëS } \\
-+\mathbb{E} \\
\left.c^{3} 0\right\} \\
\mid b\end{array}$ & kamiiiii & $\begin{array}{l}\text { K@putam } \\
\text { ○ Binj@i }\end{array}$ & Gagal \\
\hline 2 & 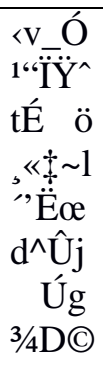 & $\begin{array}{c}\text { kaputam } \\
\text { a }\end{array}$ & $\begin{array}{l}\text { ILOVEST } \\
\text { MIKKAP } \\
\text { UTAMA } \\
\text { BINJAI }\end{array}$ & Berhasil \\
\hline 3 & $\begin{array}{l}\mathrm{E}^{1 / 2} \\
6^{\wedge} \times^{\prime} \\
\hat{Y}^{\prime} \mathrm{J} \\
\hat{\mathrm{U} G t y ́} \\
€:\left.£\right|^{1}\end{array}$ & $\begin{array}{c}\text { kamika } \\
\text { mi }\end{array}$ & $\begin{array}{l}\text { Teknik } \\
\text { Informati } \\
\text { ka }\end{array}$ & Berhasil \\
\hline
\end{tabular}

\begin{tabular}{|c|c|c|c|c|}
\hline 4 & 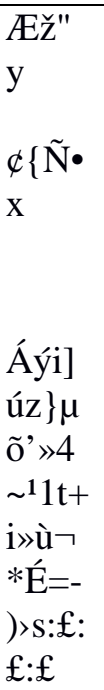 & $\begin{array}{c}\text { kakakak } \\
\text { a }\end{array}$ & $\begin{array}{l}\text { Sekolah } \\
\text { Tinggi } \\
\text { Manajem } \\
\text { en } \\
\text { Informati } \\
\text { ka dan } \\
\text { Komputer }\end{array}$ & Berhasil \\
\hline 5 & $\begin{array}{l}2 \div\{( \\
\tilde{n}-\ddot{Y}\end{array}$ & $\begin{array}{c}1609201 \\
6\end{array}$ & STMIK & Berhasil \\
\hline
\end{tabular}

\section{KESIMPULAN DAN SARAN 5.1 Kesimpulan}

Setelah melakukan tahap penelitian, perancangan, dan tahap implementasi terhadap pengamanan file dengan sistem kriptografi dimana enkripsi file dengan menggunakan algoritma Vigenere Cipher dan algoritma Hill Cipher diperoleh kesimpulan bahwa :

1. Kunci yang digunakan untuk mengenkripsi harus sama dengan kunci yang digunakan untuk melakukan dekripsi. Apabila kunci yang diinputkan tidak sama, maka hasil dari dekripsi tidak akan sama dengan plainfile semula seperti sebelum dienkripsi.

2. Algoritma Vigenere Cipher dan Algoritma Hill Cipher digunakan untuk melindungi file berupa file, dalam hal ini penulis masih menguji sebatas file TXT, DOCX dan XLSX.

3. Hasil dekripsi dari cipherfile akan menghasilkan plainfile yang sama dengan plainfile sebelum dienkripsi.

\subsection{Saran}

Berdasarkan kesimpulan diatas maka menggemukakan beberapa saran yang diharapkan dapat menjadi masukan bagi kemajuan sistem yang akan datang. Dan 
beberapa saran yang akan dikemukakan adalah sebagai berikut :

1. Sistem ini menggunakan Algoritma Vigenere Cipher dan Algoritma Hill Cipher, kunci dari Algoritma Hill Cipher menggunakan matriks berordo $2 \times 2$ dan kunci matriks tersebut telah ditetapkan oleh sistem, sehingga untuk pengembangan selanjutnya dapat mengenkripsi dan dekripsi dengan user yang menginputkan matriks serta menggunakan matriks berordo $3 \times 3,4 \times 4$ .... nxn.

2. File yang dapat dienkripsi dan dekripsi didalam sistem ini hanya file dengan ekstensi txt, docx dan xlsx. Untuk pengembangannya agar bisa menggunakan file dengan jenis ekstensi lainnya.

\section{UCAPAN TERIMA KASIH}

Kami menyampaikan terima kasih yang sebesar-besarnya kepada Ketua Yayasan Pendidikan Teknologi Informasi Mutiara atas dukungan dana berupa hibah penelitian bagi dosen STMIK KAPUTAMA tahun anggaran 2016. Kami juga mengucapkan terimakasih kepada mitra Ketua STMIK KAPUTAMA dan Ketua LPPM STMIK KAPUTAMA, yang telah melakukan arahan dalam pelaksanaan penelitian ini.

\section{DAFTAR PUSTAKA}

[1] Ariyus, 2008. Pengantar Ilmu Kriptografi: Teori Analisis \& Implementasi. Andi, Yogyakarta.

[2] Ariyus, 2006. Kriptografi Keamanan Data dan Komunikasi. Andi, Yogyakarta.

[3] Sadikin, 2012. Kriptografi untuk Keamanan Jaringan. Andi , Yogyakarta.

[4] Sugiarti, 2013. Analisis dan Perancangan UML Generated VB.06. Graha Ilmu, Yogyakarta.

[5] Yatini B, 2010. Flowchart, Algoritma, dan Pemrograman menggunakan Bahasa C++ Builder. Graha Ilmu ,Yogyakarta. 